\title{
Pengaruh Abdominal Stretching Exercise Terhadap Penurunan Intensitas Nyeri Haid Pada Remaja Putri
}

\author{
Faridah BD ${ }^{1}$, Haspita Rizki Syurya Handini ${ }^{2}$, Revina Dita ${ }^{3}$ \\ 1,2,3 Poltekkes Kemenkes Padang \\ Jalan Raya Siteba, Surau Gadang Kecamatan Nanggalo Padang, 25146 \\ Email :1 faridahbd140@gmail.com, ${ }^{2}$ haspita.rizki@gmail.com, ${ }^{3}$ revinadita27@gmail.com
}

\begin{abstract}
Abstrak
Di Indonesia, lebih dari 55\% perempuan mengalami dismenore dan angka kejadian di Sumatera Barat mencapai 57,3\%. Dismenore mengakibatkan 10\% remaja putri kesulitan dalam beraktivitas, seperti tidak konsentrasi dalam belajar atau bahkan tidak hadir di sekolah. Abdominal stretching exercise merupakan terapi alternatif yang dapat digunakan untuk menurunkan intensitas nyeri haid pada remaja putri di SMPN 1 Sungai Beremas Kabupaten Pasaman Barat Tahun 2019. Jenis penelitian ini adalah preexperiment design dengan pendekatan one group pretest posttest design dan dari populasi sebanyak 84 remaja putri yang nyeri haid didapat sampel sebanyak 16 orang secara purposive sampling. Penelitian dilakukan dari bulan Oktober 2018 sampai Juni 2019. Data dikumpulkan dengan cara mengukur intensitas nyeri menggunakan numeric rating scale. Analisis data terdiri dari univariat dan bivariat menggunakan komputerisasi dengan uji $t$ dependen. Hasil penelitian didapatkan rata-rata nyeri haid sebelum dan sesudah dilakukan abdominal stretching exercise adalah 4,88 dan 2,69. Selain itu, hasil penelitian ini menunjukkan bahwa ada pengaruh abdominal stretching exercise terhadap penurunan intensitas nyeri haid dengan $p$ value =0,000.Berdasarkan hasil analisis diatas, dapat disimpulkan bahwa abdominal stretching exercise efektif dalam menurunkan intensitas nyeri haid.
\end{abstract}

Kata kunci: Dismenore, nyeri haid, abdominal stretching exercise

\section{Effect of Abdominal Stretching Exercise For Reducing Menstrual Pain The Intensity of Adolescent Girl}

\begin{abstract}
In Indonesia, more than 55\% women suffered from dysmenorrhea, and prevalence in West Sumatera is about 57,3\%. Dysmenorrhea makes $10 \%$ adolescent girls have difficulty when doing activity, such as either who can't concentration for study or absent for school. Abdominal stretching exercise is an alternative therapy which can have used for reducing menstrual pain intensity of adolescent girl at SMPN 1 Sungai Beremas Kabupaten Pasaman Barat on 2019. This study is a pre-experiment with one group pretestposttest design and from 84 adolescent population girls who experience dysmenorrhea obtained of 16 by purposive sampling. This study begins from October 2018 until Juni 2019. The data collected by measuring pain intensity with numeric rating scale. The analysis data consisted of univariate and bivariate using computerized with dependent t-test.The result is the mean of menstrual pain before and after doing abdominal stretching exercise are 4,88 and 2,69. Then, the result shows that there was an effect of abdominal stretching exercise for reducing menstrual pain with $p$-value $=0,000$. The conclusion based on the analysis above that abdominal stretching exercise is effective in reducing menstrual pain.
\end{abstract}

Keywords: Dysmenorrhea, menstrual pain, abdominal stretching exercise 


\section{PENDAHULUAN}

Manusia adalah makhluk yang tumbuh dan berkembang, salah satu tahap pertumbuhan dan perkembangannya adalah masa remaja. Perbedaan pertumbuhan fisik laki-laki dan perempuan adalah pada pertumbuhan organ reproduksi dan penampilan yang berbeda, serta bentuk tubuh yang berbeda akibat berkembangnya tanda seks primer maupun sekunder. Pada remaja perempuan terjadi perubahan primer dan sekunder, yang mana ciri dari perubahan seks primer adalah organ reproduksi wanita tumbuh selama masa pubertas dan terjadinya menstruasi. Menstruasi yang dialami para remaja wanita dapat menimbulkan masalah, salah satunya adalah dismenore.

Dismenore merupakan masalah ginekologis yang paling umum dialami wanita usia remaja. Keluhan yang dirasakan biasanya adalah merasa nyeri pada perut bagian bawah dan menjalar sampai ke punggung serta paha. Angka kejadian dismenore di dunia sangat besar lebih dari $50 \%$ perempuan di setiap negara mengalami dismenore. Penelitian di China tahun 2010 yang dilakukan oleh Gui-Zhou dalam Sormin (2014), menunjukkan sekitar 41,9\% sampai $79,4 \%$ remaja mengalami dismenore primer, dimana $31,5 \%$ sampai $41,9 \%$ terjadi pada usia 9-12 tahun, dan $57,1 \%$ sampai $79,4 \%$ pada usia 13-18 tahun. Di Indonesia diperkirakan mencapai $55 \%$ perempuan usia produktif yang tersiksa oleh nyeri selama menstruasi dimana angka kejadian (prevelensi) dismenore sebesar $64,25 \%$ yang terdiri dari $54,89 \%$ dismenore primer dan 9,36\% dismenore sekunder. Sedangkan di Sumatera Barat, angka kejadian dismenore mencapai 57,3\%.

Dismenore merupakan penyebab paling sering alasan ketidakhadiran di sekolah dan pengurangan aktivitas sehari - hari. Menurut Fidiarti (2018), sekitar 70-90\% kasus nyeri haid terjadi saat usia remaja dan sekitar $10 \%$ remaja yang mengalami nyeri haid akan mempengaruhi aktivitas akademik dan sosialnya. Menurut penelitian Woo dan Mc Eneaney pada tahun 2010, dismenore mempengaruhi kualitas hidup sebesar 40-90\% wanita, dimana satu dari tiga belas wanita yang mengalami dismenore tidak hadir bekerja dan sekolah selama 1-3 hari perbulan. Menurut penelitian Nathan pada tahun 2011, menyatakan bahwa 30-60\% wanita mengalami dismenore, dan 7-15\% tidak dapat pergi ke sekolah atau bekerja. Untuk mengatasi kondisi seperti ini dapat dilakukan dengan terapi farmakologi dan non farmakologi. Terapi non farmakologi lebih banyak dipilih karena lebih aman bila dibandingkan dengan terapi farmakologi, salah satunya yaitu abdominal stretching exercise.

Abdominal stretching exercise merupakan sesuatu latihan peregangan otot terutama pada bagian perut yang dilakukan selama 10 menit. Abdominal stretching exercise membantu meningkatkan perfusi darah ke uterus dan merileksasikan otot-otot uterus, sehingga tidak terjadi metabolisme anaerob (seperti glikolisis dan glikogenolisis) yang akan menghasilkan asam laktat, dimana jika terjadi penumpukan asam laktat akan menyebabkan kelelahan/nyeri/kram pada otot. Penumpukan asam laktat tersebut dapat dikurangi dengan proses oksidasi sehingga diperlukan terapi alternatif untuk melancarkan aliran darah yang membawa oksigen untuk menghilangkan kelelahan otot tersebut. Berdasarkan penelitian yang dilakukan oleh Salbiah pada tahun 2012 terbukti bahwa penurunan tingkat nyeri menstruasi dapat diatasi melalui latihan abdominal stretching, diperoleh hasil sebelum perlakuan skala nyeri sedang sebanyak $66,1 \%$ dan setelah dilakukan perlakuan berubah menjadi skala nyeri ringan dengan hasil 89,3\%.

Berdasarkan hasil studi pendahuluan yang telah dilakukan oleh peneliti di SMPN 1 Sungai Beremas Kabupaten Pasaman Barat pada bulan Oktober 2018 terhadap 10 orang siswi dengan menggunakan skala ukur numerik (Numeric Rating Scale), didapatkan 8 orang mengalami dismenore dan 2 orang lainnya tidak mengalami 
dismenore. Pada 8 orang tersebut mengaku mengalami nyeri ringan sebanyak 3 orang $(37,5 \%)$, nyeri sedang 4 orang $(50 \%)$, dan nyeri berat 1 orang $(12,5 \%)$. Dari yang mengalami dismenore, penanganan yang dilakukan untuk mengurangi rasa nyeri tersebut yaitu 1 orang siswi mengkonsumsi obat penghilang rasa nyeri, 3 orang beristirahat atau tidur, 2 orang dengan menggunakan minyak kayu putih, dan 2 orang membiarkan rasa nyeri tersebut sambil menangis. Dari data tersebut tidak ada siswi yang mengetahui maupun melakukan penanganan nyeri haid dengan latihan fisik terutama abdominal stretching exercise.

Tujuan penelitian ini adalah untuk mengetahui pengaruh abdominal stretching exercise terhadap penurunan intensitas nyeri haid pada remaja putri di SMPN 1 Sungai Beremas Kabupaten Pasaman Barat Tahun 2019.

\section{METODE PENELITIAN}

Jenis penelitian yang digunakan adalah kuantitatif preexperiment design dengan pendekatan one group pretest posttest design yang dilakukan di SMPN 1 Sungai Beremas Kabupaten Pasaman Barat pada bulan Oktober 2018-Juni 2019. Populasi dalam penelitian ini adalah siswi SMPN 1 Sungai Beremas yang mengalami nyeri haid berjumlah 84 orang dan dengan menggunakan teknik purposive sampling dipilih 16 orang responden yang sesuai dengan criteria inklusi yaitu siswi yang memiliki siklus haid yang teratur tiap bulan, bersedia tidak menggunakan terapi farmakologi maupun non farmakologi selain terapi yang ditetapkan peneliti selama penelitian, bersedia mengikuti prosedur penelitian dan bersedia menjadi responden, sedangkan yang mengalami dismenore berat dan dismenore sekunder dikeluarkan dari penelitian ini. Pengukuran intensitas nyeri haid dapat menggunakan Numeric Rating Scale (NRS). Analisis univariat dilakukan untuk mengetahui rata-rata dan standar deviasi intensitas nyeri haid sebelum dan sesudah diberikan perlakuan abdominal stretching exercise, sedangkan analisis bivariat dilakukan untuk mengidentifikasikan hubungan antara intensitas nyeri haid sebelum dan sesudah diberi perlakuan abdominal stretching exercise. Uji statistik yang digunakan adalah t-test dependent dengan tingkat kepercayaan (CI) 95\% dengan nilai $\alpha=0,05(\mathrm{p} \leq 0,05)$.

\section{HASIL DAN PEMBAHASAN}

Tabel 1. Rata-Rata Intensitas Nyeri Haid Sebelum Dilakukan Abdominal Stretching Exercise

\begin{tabular}{llll}
\hline Variabel & Mean & Min-Max & $\begin{array}{l}\text { Std. } \\
\text { Deviation }\end{array}$ \\
\hline Pretest & 4,88 & $2-8$ & 1,628 \\
\hline
\end{tabular}

Berdasarkan tabel 1, hasil analisis ratarata nyeri haid yang dialami oleh responden sebelum melakukan abdominal stretching exercise adalah 4,88 dengan nilai minimum 2 dan nilai maksimum 8 serta standar deviasi 1,628. Sebelum dilakukan intervensi, keluhan yang umumnya dirasakan oleh responden adalah nyeri perut bagian bawah kram, sakit pinggang, kepala pusing dan mual.

Remaja dengan dismenore akan mengalami kram pada saat menstruasi terutama pada abdomen bagian bawah yang bersifat kronis dan siklik. Pada waktu otot berkontraksi, peredaran darah dalam otot terhenti oleh karena pembuluh-pembuluh darah di dalam otot terjepit. Kontraksi otot tersebut memicu terjadinya peningkatan kadar kalsium dan ion fosfat anorganik intramuscular yang akan merangsang pemecahan glikogen (glikogenolisis). Dengan menurunnya kadar glikogen otot maka akan meningkatkan kebutuhan ambilan glukosa dari darah untuk dipecah (glikolisis). Kontraksi yang kuat dan lama pada dinding uterus menyebabkan terjadi kelelahan/kram otot yang disebabkan karena menumpuknya kadar asam laktat sebagai akibat dari proses metabolisme anaerob (glikolisis dan glikogenolisis). 
Penumpukan asam laktat tersebutlah yang menyebabkan kram otot pada bagian abdomen sehingga timbul nyeri perut saat haid. Selain itu, pendapat lain mengatakan dismenore primer disebabkan oleh faktor lain seperti faktor endokrin dimana saat haid endometrium dalam fase sekresi akan memproduksi prostaglandin F2 alfa yang menyebabkan kontraksi otot polos pada rahim dan jika jumlah prostaglandin F2 alfa tersebut dilepaskan berlebih dalam darah maka selain kram perut, dijumpai pula efek lain seperti pusing, mual, dan muntah.

Menurut peneliti, banyaknya responden yang mengalami nyeri haid di skala 4-6 (nyeri sedang) disebabkan juga karena adanya faktor lain yang berperan seperti faktor psikologis. Dimana menurut teori, remaja yang secara emosional tidak stabil, apalagi mereka masih SMP dan baru mengalami haid serta belum mendapat penerangan yang baik tentang proses menstruasi akan mudah mengalami dismenore primer.

Tabel 2. Rata-Rata Intensitas Nyeri Haid Sesudah Dilakukan Abdominal Stretching Exercise

\begin{tabular}{cccl}
\hline Variabel & Mean & $\begin{array}{l}\text { Min- } \\
\text { Max }\end{array}$ & $\begin{array}{l}\text { Std. } \\
\text { Deviation }\end{array}$ \\
\hline Posttest & 2,69 & $0-6$ & 1,815 \\
\hline \multicolumn{2}{c}{ Berdasarkan } & tabel & 2, hasil analisis
\end{tabular}

rata-rata nyeri haid yang dialami oleh responden sesudah melakukan abdominal stretching exercise adalah 2,69 dengan nilai minimum 0 dan nilai maksimum 6 serta standar deviasi 1,815. Setelah dilakukan abdominal stretching exercise selama 10 menit, responden mengungkapkan bahwa terdapat penurunan nyeri haid yang dirasakan pada perut bagian bawah yang sebelumnya kram menjadi lebih relaks. Gerakan dari latihan peregangan pada otot abdominal dan lumbal bagian bawah akan memberikan tekanan pada pembuluh darah besar di abdomen yang selanjutnya akan meningkatkan volume darah yang mengalir ke seluruh tubuh termasuk organ reproduksi. Hal tersebut dapat memperlancar supply oksigen ke pembuluh darah yang mengalami vasokontriksi, sehingga nyeri haid dapat berkurang.

Menurut peneliti, abdominal stretching exercise memiliki pengaruh bagi responden dalam mengurangi nyeri haid karena semua responden tepat dalam melakukan gerakan sesuai dengan pedoman latihan dan mengikuti instruksi dari peneliti. Selain itu, gerakan abdominal stretching exercise yang tidak terlalu sulit dan mudah dilakukan serta gerakan yang langsung ke bagian abdominal sehingga dapat memberikan efek dalam menurunkan nyeri haid pada responden.

\section{Tabel 3. Pengaruh Abdominal Stretching Exercise Terhadap Penurunan Intensitas Nyeri Haid}

\begin{tabular}{llllllll}
\hline & \multirow{2}{*}{ N } & & & \multicolumn{2}{l}{$95 \%$ CI of the } & \\
& & & Corre & \multicolumn{2}{l}{ Difference } & $p$ \\
\cline { 5 - 6 } & & & lation & Lower & Upper & value \\
\hline Pretest- & 16 & 2,188 & 0,933 & 1,838 & 2,537 & 0,000 \\
Posttest & & & & & & \\
\hline
\end{tabular}

Berdasarkan tabel 3, hasil analisis bivariat dengan uji t-test dependent diperoleh nilai mean sebelum dan sesudah abdominal stretching exercise adalah 2,188. Dari uji tersebut didapatkan nilai $p$ value sebesar 0,000 . Nilai $p$ value yang diperoleh $<0,05$ maka Ho ditolak dan Ha diterima artinya ada pengaruh abdominal stretching exercise terhadap penurunan intensitas nyeri haid pada remaja putri. Prinsip yang mendasari penurunan nyeri haid yaitu abdominal stretching exercise membantu meningkatkan perfusi darah ke uterus dan merileksasikan otot-otot uterus, sehingga tidak terjadi metabolisme anaerob (seperti glikolisis dan glikogenolisis) yang akan menghasilkan asam laktat, dimana jika terjadi penumpukan asam laktat akan menyebabkan nyeri/kram pada otot. Penumpukan asam laktat tersebut dapat dikurangi dengan proses oksidasi sehingga diperlukan terapi alternatif seperti abdominal stretching exercise untuk melancarkan aliran darah yang membawa oksigen. Dengan begitu terjadilah proses oksidasi yang menurunkan kadar asam laktat 
dan dapat merelaksasikan otot perut yang kram sehingga nyeri haid dapat berkurang.

Berdasarkan hasil penelitian yang peneliti lakukan, terjadi penurunan rata-rata nyeri haid setelah dilakukan abdominal stretching exercise dari 4,88 menjadi 2,69, dimana penurunan ini tidak terlalu signifikan. Menurut peneliti, penurunan rata-rata nyeri yang tidak terlalu signifikan tersebut disebabkan karena adanya faktor lain penyebab nyeri haid selain faktor fisiologis yaitu faktor psikologis seperti stres. Stres yang dialami oleh remaja bisa disebabkan oleh banyak hal diantaranya stres dapat dipicu karena akan menghadapi ujian, khususnya kelas IX yang akan menghadapi ujian nasional, ataupun karena masalah hubungan sosial dengan lingkungan baik di rumah maupun di sekolah. Menurut peneliti, abdominal stretching exercise merupakan terapi non farmakologi yang efektif digunakan dalam mengurangi nyeri haid karena gerakan yang mudah dilakukan dan aman karena menggunakan fungsi fisiologis tubuh serta tidak memerlukan alat dalam pelaksanaannya.

\section{SIMPULAN}

Berdasarkan penelitian yang peneliti lakukan tentang pengaruh abdominal stretching exercise terhadap penurunan intensitas nyeri haid pada remaja putri di SMPN 1 Sungai Beremas Kabupaten Pasaman Barat Tahun 2019 dapat ditarik kesimpulan sebagai berikut: ratarata nyeri haid sebelum melakukan abdominal stretching exercise adalah 4,88 dengan skala nyeri maksimum 8 dan skala minimum 2 , ratarata nyeri haid setelah melakukan abdominal stretching exercise adalah 2,69 dengan skala nyeri maksimum 6 dan skala minimum 0 , dan terdapat pengaruh abdominal stretching exercise terhadap penurunan intensitas nyeri haid pada remaja putri di SMPN 1 Sungai Beremas Kabupaten Pasaman Barat Tahun 2019.

\section{UCAPAN TERIMAKASIH}

Peneliti mengucapkan terimakasih kepada para informan dan responden yang telah berpartisipasi dalam penelitian ini serta Tim Peneliti yang telah bekerjasama sehingga penelitian ini dapat berjalan dengan baik.

\section{DAFTAR PUSTAKA}

Fauziah, Mia Nur. 2015. Pengaruh Latihan Abdominal Stretching Terhadap Intensitas Nyeri Haid (Dismenore) pada Remaja Putri di SMK Al Furqon Bantarkawung Kabupaten Brebes. [diakses tanggal 26 September 2018]. Tersedia dari: http://ejournal.uinsyahid.ac.id

Fidiarti, Mey, dkk. 2018. Pengaruh Latihan Abdominal Stretching Dan Musik Klasik Terhadap Intensitas Nyeri Haid Pada Remaja Putri. [diakses tanggal 1 Oktober 2018]. Tersedia dari: http://ejournal.stikesalirsyad.ac.id

Kumalasari, Mei Lina Fitri. 2017. Efektivitas Senam Dismenore Sebagai Terapi Alternatif Menurunkan Tingkat Nyeri Haid Tinjauan Sistematis Penelitian Tahun 2011-2016. [diakses tanggal 28 September 2018]. Tersedia dari: http://ejournal.uinsunanampel.ac.id

Sormin, Nancy Monika. 2014. Efektivitas Senam Dismenore Dalam Mengurangi Dismenore Pada Remaja Putri Di SMP Negeri 2 Siantan Kabupaten Pontianak. [diakses tanggal 29 September 2018]. Tersedia dari: http://ejournal.univtp.ac.id Setyorini, Yuyun. 2014. Efektifitas Senam Dengan Modul Dalam Mengurangi Dismenore Pada Remaja SMA Di Kota Surakarta. [diakses tanggal 29 September 2018]. Tersedia dari: http://ejournal.poltekkes-surakarta.ac.id

Salbiah. 2012. Penurunan Tingkat Nyeri Saat Menstruasi Melalui Latihan Abdominal Stretching. diakses tanggal 29 September 2018]. Tersedia dari: http://ejournal.unsyiah.ac.id 
Windastiwi, Weny, dkk. 2017. Pengaruh Abdominal Stretching Exercise Terhadap Intensitas Nyeri Dismenorea. [diakses tanggal 29 September 2018]. Tersedia dari: http://ejornalkebidanan.ac.id

Arifiani, Ayu. 2016. Efektivitas Latihan Peregangan Perut (Abdominal Stretching Exercise) Dalam Mengurangi Dismenore Pada Remaja Putri Di SMA Panca Bhakti Pontianak. [diakses tanggal 2 Oktober 2018]. Tersedia dari: http://ejournal.univtp.ac.id

Abunawas, Dian Wardina S. 2017. Perbedaan Pengaruh Stretching Dan Massage
Effleurage Terhadap Penurunan Nyeri Haid Pada Mahasiswi Fisioterapi Di UNISA Yogyakarta. [diakses tanggal 2 Oktober 2018]. Tersedia dari: http://ejournalunisa.ac.id

Fikriyah, Ulfatun. 2017. Penerapan Abdominal Stretching Terhadap Penurunan Intensitas Nyeri Dismenore Remaja Putri Di BPM Hj Nuryamah Kutowinangun Kabupaten Kebumen. [diakses tanggal 2 Oktober 2018]. Tersedia dari: http://ejournalkebidanan.co.id 